\title{
The Myanmar Case Study: A Practitioner's Viewpoint of the Deconstruction and Reconstruction of Leadership in the Era of Digital Convergence and an Agenda for Future Enquiry
}

\author{
Dr. Teck Choon TEO,DBA \\ Associate Dean, RVi Institute, Mandalay, Myanmar \\ Fellow, Chartered College of Teaching, UK \\ Prof. Dr. Kim Cheng Patrick, LOW, Ph.D \\ Chartered Marketer, Certified MBTI Administrator \\ \& Certified Behavioural Consultant \\ Visiting Professor (HRM/Strategic Management) \\ University of South Pacific
}

\begin{abstract}
This paper features an in-depth look at how a leader can advance in the chosen career path by changing the leadership style, in response to changing business priorities, as influenced by uncertain economic times. We can see how leadership style calls for flexibility because of the complex nature of the problems that every leader continually confronts. It is assumed that the kind of leadership style employed in an organization has an impact on its overall performance. Qualitative case study design was employed. Purposive sampling was adopted to sample a total sample size of 22 respondents who are in leadership position from various fields of industries. The paper is organised into five sections. The first gives a brief introduction of the literature on leadership. The second explores the literature review of leaders at the core. The third investigates the critical success dynamics, specifically on leadership continuum and how that contributes to the development of a global leader. The fourth examines the role of leadership, specifically an adaptation worldview, in the development of a global leader from a practitioner's view from Myanmar. The fifth considers the challenges in managing relationship and leverage global leadership development.
\end{abstract}

Key words: leadership styles, global leadership, digital transformation, globalisation

\section{Introduction}

Over the past decade and a half, government and business leaders including laymen have witnessed a major digital transformation. The growth in the prominence of digital, social media and mobile (DSMM) marketing has paralleled technological innovations, such as the increasing penetration of home Internet and affordable high-speed broadband connections, the development of social media platforms such as Facebook, Instagram and widespread consumer adoption of "smart" mobile devices. Such innovation has also influenced the ways that consumers behave across all types of market settings. For example, just as the rapid growth in mobile adoption has opened new marketing communications and targeting possibilities, the ubiquity of social media has changed how people share information with each other and interacts (Ho \& Teo 2019). Thus, the digital transformation and leadership over the past 15 years is reflected in the ways that firms and people have embraced new technologies.

The present paper takes this as its goal. It should be noted from the outset that the purpose is not to provide a comprehensive literature review of the growing body of leadership and digital leadership in a modernistic or postmodernistic work or to cite every article in this domain. The breadth of the topics that now exist make such an undertaking infeasible in a single article.

We begin by stating that the study of leadership with its varying styles has been extensively studied, and is an on-going process for many decades. It can be broadly defined as a process of social influence. Importantly, leadership, unlike management, does not dependent on position, status or privilege but rather it is an observable, understandable, and learnable set of skills that can be mastered by anyone who is willing to take the time and efforts to acquire them (Shamir and Eilam-Shamir 2018). It has been proposed by various authors that few terms inspire less agreement than the definition of leadership vis-à-vis if you believe that leadership is a dynamic process of interaction amongst and between people, then a clear definition is neither feasible nor practical. Bass suggested in 1990 there may be as much definition as there are writers on the subject (Kreitner \& Kinicki 2001). Yukl also remarked on the numerous definitions that the differences are not just a case of fault-finding but they reflect a deep disagreement about identification of leaders and leadership processes (Yukl, 1998). 
Nevertheless, any discussion on leadership demands a definition/proposition be put forth as a part of the argument. Hence, the following definition/proposition is put forth as a part of our discussion (see Figure 1):

(a) The capacity and competence to create a vision and then communicate that vision to others to share in making that vision a reality which imply that leadership is dynamic and that leadership is not a function of level or position.

(b) Furthermore, leaders have certain fundamental beliefs and attributes which undergird honesty and ethical behaviour.

(c) Leadership styles and actions differ across cultural and organisational boundaries and because of huge differences, there needs to be leadership abilities and knowledge that move across the cultural and organizational boundaries to assist in growing the organization.

(d) The failure to effectively conduct digital transformation will stifle the company's ability to compete.

Leadership is having the capacity to influence people by setting and inspiring example (Ganta andManukonda 2014, Low, 2018; 2013). The example is one that inspires people to pursue goals that ultimately bring gains to the organisation. Typically, leadership involves creating a vision of the organisational future, devising a strategy for achieving that vision, and communicating that vision to all members of the organisation (Wuestman and Casey, 2015).

An increasingly connected world has fast-forwarded the rate of information transfer across the globe. Social media has provided the platform for consumers to communicate simultaneously not only with their friends and acquaintances, but also with relative strangers with unprecedented ease(Friedman, 2007). Globalisation has affected all aspects of practical, economic and social life. Nor can anyone overlook the technological changes and their impact on the speed of information transmission, the ease of availability and the low cost. Understanding the interaction between leadership style and the appropriate leadership implementation is central for developing organisational performance and galvanising high level of employee performance. Many organisations have begun to move away from conventional leadership modus operandi and now require varieties of skillsets and leadership styles that can adapt to persistent environmental changes. Globalisation is here to stay, so changes have become important for organisations to cope with competition.

\subsection{Digital Imperative}

On another hand, digital leadership can be described as the strategic use of a company's digital assets to achieve business goals. It is about what the digital leader does to take advantage of company's own digital assets to gain and sustain a competitive advantage. Unsurprisingly, digital leaders are willing to explore how information technology (IT) can facilitate company becoming more responsive to customer needs and changing business requirements. Above all, successful digital leaders understand how significantly important and the willingness to manipulate data (both inwards/outwards) triggered across the various ecosystems in which it operates. Hence, the digital leader will recognise that digital transformation is not about technology but about strategy, structure, culture, capabilities and understanding its customers (Kreutzer et al 2018). Skilled digital leadership is essential to transform business organisations to be fit for the Internet-era, through a process of building new capacities, structures and ways of working.

In the same vein, today's information technology (IT) organisations, new roles are evolving to deal with digital business (Fitzgerald et al 2013), for example the chief data officer (CDO), the chief trust officer (CTO), the data management executive and the information governance lead. All these titles are jockeying to plug the current void in corporate leadership and to assure the quality and the functional value of information. Given the future of digital leadership, senior leadership vis-a-vis CIOs, CEOs need to recalibrate their roles in business by stepping forward in assuming the responsibilities of digital leadership. They have access to the technology and the data needed to assume accountability and deliver digital value across the company. Using the information for continuous learning is the lifeblood for business. How to manage learning within the extended enterprise has thus become a key strategic challenge (Kreutzer et al 2018). 


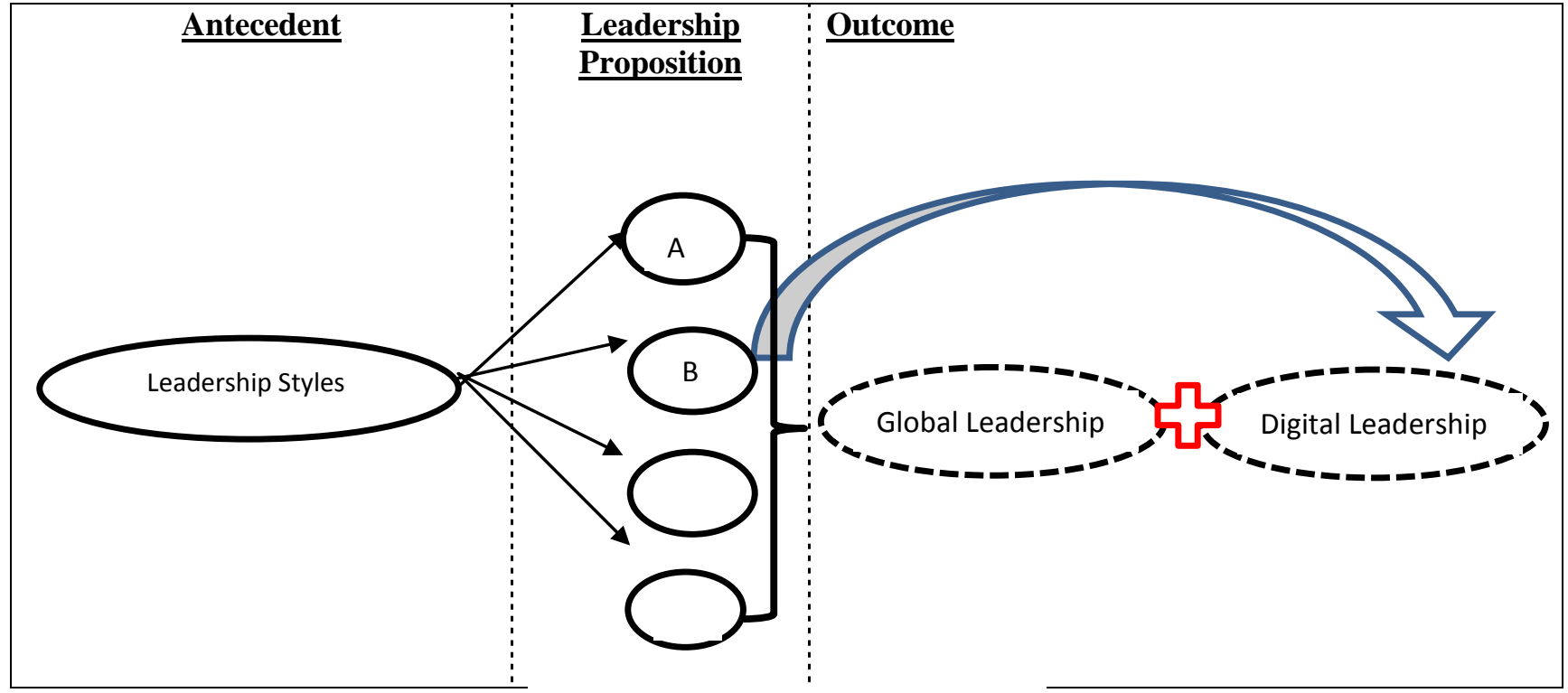

Figure 1: The conceptual framework

\section{Literature Review}

\subsection{Leaders at the Core}

Defining the content domain of intercultural competence for leaders in a global context can be problematic (Bird et al 2010) and rightly so, as global leaders are an embryonic segment of professionals that are proficient in managing business at global arena and in multicultural contexts. The prerequisite is having the tenacity to stimulate people to surmount obstacles. In turn, inspires visionary initiatives that transcend national boundaries. Furthermore, global leaders must recognise the impact of their actions on surrounding communities and stakeholders. The realisation of personal prosperity is dependent upon the prosperity of others in a larger context.

The global leadership development remains a challenging theoretical problem in the field of global leadership. To simplify this issue, it is important to understand that the development of leadership competency involves adopting and enhancing intercultural competencies associated with global leadership. In addressing the cultural element organisations, one can determine if they are strong or weak in the areas that deal with local and regional cultures throughout the globe. And by understanding these aspects, an organisation will be able to have a seamless integration with strategic partners or communities throughout the world without the enormous pressure to accomplish this integration and without the knowledge of how to accomplish the goals.

Unsurprisingly, the biggest challenge that global leaders face today relates to talent and future leadership. Millennials, now at the cusp of assuming leadership roles, and they often rate their intellectual curiosity higher than other generations; are more likely to seek feedback and input from colleagues and mentors and likely to want "stretch" assignments." Oftentimes, the leadership of an enterprise is in jeopardy when little attention is given to how power or the capacity to inspire subordinates and peers is used. (Montana \& Charnov, 2008). The leadership process itself can become a monologue when detached from the organisation's mission, its people and the culture it permeates. The leader will remain ineffective and futile, despite advanced degrees, so long as the science and art of influencing people continue to be taught in a momentous vacuum.

Leadership within organisations is only attainable through the combination and use of power and authority. As discussed by Ganta and Manukonda (2014), leadership is a kind of power where one person has the ability to influence or change the values, beliefs, behaviour and attitudes of another person. Problems always arise when power is imposed without the backing of authority, which almost invariably is opposed. Person with strong leadership ability exhibits good example or role model to their workers, because the leader has the competence and capacity to achieve positive outcomes and gains the trust and admiration of their workers(Lee et al., 2010). This inadvertently changes their values, beliefs, behaviour and attitudes (Grint, 2007). This is also supported by Northhouse (2009), who argues that leaders who possess strong leadership have the strength to influence others to achieve the goals and objectives of the organization. Accordingly (Wasim \& Imran 2010; Jackson \& Parry 2008 advised that) the hallmark of effective leaders is that they give a clear direction to their employees, and facilitate their employees to commit to their tasks and to develop teamwork or group to realise the organisation's goals and objectives. 
This gives us a picture that good leaders usually have a clear vision for the company and therefore can easily identify the problems and obstacles that currently stand between them and the aims of the organisation. Thus they are able to effectively and efficiently generate the necessary improvements that will navigate the company into the future while keeping abreast with contemporary changes in the business world.

By contrast, while too often we can find authoritative people who do not have vested positions of authority, we frequently find people who are in a position of authority, but are powerless to influence the behaviour of others. Leadership can be learned, and power can be developed, but in imbuing an effective leader, intuitively one must be able to discern from the various forms of power and select the one most in line with his or her leadership style, character traits and working environment (Goncalves 2013).

\subsection{Developing global leadership model}

An effective leadership can bring about positive change that helps the organisation to improve and innovate in the current business environment. Global leadership is one of the principal factors in bringing constructive change to the organisation (Park et al, 2018, Jeong et al, 2017); if there is no leadership in the organisation, it will be an invitation to futility, hence unable to change the course they desire and experience negative change instead.

Previous research by Ford \& Kiran (2008) suggested that there has also been a convergence of what is perceived to be effective leadership around the globe, which has become more aligned with that of western-driven ideas. At the same time, identifying divergent, indigenous leadership that is effective in a specific culture has also been increasingly emphasised. These theoretical and construct problems contribute to the global leadership development gap. Nevertheless, the global leadership literature has advocated that a diverse array of leadership skills, attributes, and mindset may exist for global leaders to adapt to the growth, necessarily including components of both globally acceptable and indigenously unique characteristics (Morrison, 2000).

\section{Methodology}

The study employed qualitative case study design to collect and analyse the data. It involved in-depth interviews (oneon-one interviews) to facilitate understanding of future leadership construct (Kegler et al 2019). This approach holds promising directions for organisational survival and performance.

The study was conducted by means of both primary and secondary sources of data. Interviews formed the basis for the primary sources of data. A semi-structured interview guide was designed for the respondents. The respondents were put into groups according to their industry sector. Focus group discussions were then held with the respondents. Respondents' opinions were solicited on the organisation's leadership style and its impact on the performance and survival of the organisation. This allows the researchers control over the questioning approach, while giving the respondents sufficient space to provide historical and detailed information where necessary (Creswell, 2007). Also, in order to fully understand the issues being investigated, the one-on-one interview approach was adopted as it is an effective tool which offers researchers an opportunity to get in-depth information. All the focus group discussions were audio-recorded with the respondents' permission. These audio tapes were transcribed verbatim and added to other field notes and analysed manually using hand coding and highlighter pens to colour important texts. Themes so identified were then categorised into major themes with sub-themes for each of the major themes.

\subsection{Age of the respondents:}

\begin{tabular}{|c|c|c|}
\hline Age Range & $\begin{array}{c}\text { Frequency of } \\
\text { Respondents }\end{array}$ & $\begin{array}{c}\text { Percentage of } \\
\text { Respondents (\%) }\end{array}$ \\
\hline $35-44$ & 18 & 81.82 \\
\hline $45-54$ & 4 & 18.18 \\
\hline Grand Total & $\mathbf{2 2}$ & $\mathbf{1 0 0}$ \\
\hline
\end{tabular}

Table 1. Age of respondents

\subsection{Number of years worked in their organisations}

\begin{tabular}{|c|c|c|}
\hline $\begin{array}{c}\text { Number of } \\
\text { Years }\end{array}$ & $\begin{array}{c}\text { Frequency of } \\
\text { Respondents }\end{array}$ & $\begin{array}{c}\text { Percentage of } \\
\text { Respondents }(\boldsymbol{\%})\end{array}$ \\
\hline $1-3$ years & 6 & 27.27 \\
\hline $3-5$ years & 12 & 54.55 \\
\hline $5-10$ years & 4 & 18.18 \\
\hline Grand Total & $\mathbf{2 2}$ & $\mathbf{1 0 0}$ \\
\hline
\end{tabular}

Table 2. Number of years worked in their organisations 


\subsection{Trend of organisational performance over 2014 to 2019}

\begin{tabular}{|c|c|c|}
\hline $\begin{array}{c}\text { Trend of } \\
\text { Organisations }\end{array}$ & $\begin{array}{c}\text { Frequency of } \\
\text { Respondents }\end{array}$ & $\begin{array}{c}\text { Percentage of } \\
\text { Respondents (\%) }\end{array}$ \\
\hline Increasing Sales & 8 & 36 \\
\hline Stable & 8 & 36 \\
\hline Unpredictable & 2 & 9 \\
\hline No response & 4 & 18 \\
\hline Grand Total & $\mathbf{2 2}$ & $\mathbf{1 0 0}$ \\
\hline
\end{tabular}

Table 3. Trend of organisational performance over 2014 to 2019

\subsection{Relationship between leadership style and organisational performance}

\begin{tabular}{|c|c|c|}
\hline Relationship & Frequency & Percentage (\%) \\
\hline Yes & 16 & 73 \\
\hline No & 2 & 9 \\
\hline Not sure & 4 & 18 \\
\hline Grand Total & $\mathbf{2 2}$ & $\mathbf{1 0 0}$ \\
\hline
\end{tabular}

Table 4. Relationship between leadership style and organisational performance

\section{Analysis and Discussion}

\subsection{Critical Success Dynamics}

Leadership is not just about influencing the employees in the organisation, but also, providing a clear direction to the employees according to the organisation's vision and mission (Thompson, Peteraf, Gamble \& Strickland, 2017; Maxwell, 1993). Hence, the leadership spectrum chronicles the leader's strategy and thinking pattern (Lippitt, 2002). For example, a leader can galvanise staff to undertake several important tasks:

- create new products

- manage and increase clientele

- maintain a solid corporate infrastructure

- develop more efficient processes

- produce a culture that stresses performance and rewards

- monitor future opportunities and prepare for possible contingencies (Lippitt, 2002).

The world is witnessing a digital transformation and with much exposure to globalisation; and the connected world creates a digital imperative for organisations. On the other hand, a digital leader will use relevant data/information to drive analysis rather than subjective analysis and to:

- develop vision rather than aspiration

- craft employee or customer based strategy rather than regimental plans

- outline coherent action rather than disjointed performance programmes

- emphasis on outcomes rather than outputs

In particular, the digital leader will appreciate that digital transformation is not about technology but is about strategy, structure, culture, capabilities and understanding the employees or customers. There are basic fundamentals to digital leadership and must now take on board if they are to successfully drive their organisation forward in the digital age. As a result, leaders deploy a gamut of leadership styles, at different times to increase their organisation's success and their longevity in the leadership position.

\subsection{Leadership Propensities}

In an age of escalating ambiguity, the notion that leadership means being in charge of a group is obsolete or needs updating. Technological change and innovation necessitate less rigid, hierarchical concept of leadership. Wherever success depends on a diversity of ideas, leadership becomes fragmented with diminutive impacts on authority. In other words, it become imperative for the leader to deploy a specific leadership style to safely navigate his way through turbulent times and to preserve the integrity of the organisation's hierarchy. The leadership dynamic reveal how a leader can deal with organisational and economic changes. It is up to top management to deploy appropriate and suitable leadership style in a given circumstance and at the right time. 
The level 5 leadership in Jim Collins' book "Good to Great" published in 2001, is an interesting approach deviating from traditional leadership models vis getting work done through people; and is an attempt to face rising uncertainty. The vaunted humility of the level 5 leader has the origin from the awareness that no single leader has all the knowledge but the fact that they can no longer provide direction without getting input from diverse sources.

In conceptualising modern facilitative leadership, it raises an interesting question. Is it a last ditch attempt to save the status quo idea that leadership means being in charge of a group? This facilitative leadership also welcomes ideas for new directions from anywhere. To transit fully to postmodern leadership we need to recognise that eliciting ideas out of others is facilitation, not leadership. Being a facilitator is a critical role for those in charge, but a facilitator is a facilitator, not a leader.

The collaborative interactions such as brainstorming or the creation of open source software (as in the case of Apple), each idea that compel the organisation into new frontiers is a discrete leadership act. Oddly, the group or person exhibiting leadership is clearly not in charge of those who follow (Bergquist, 2008). This form of leadership is unadulterated influence vis-à-vis showing the way for others either by example or by directly advocating a better way.

\section{Discussions}

\subsection{Technology, Talent and Tolerance in Myanmar}

Myanmar is going through a metamorphic change in recent years and is playing catch-up with developed neighbouring economies like Malaysia, Thailand and Singapore. During the past few years, all kinds of new businesses are thriving in every corner of the metropolitan Yangon city both from foreign investors and local young entrepreneurs. These rising entrepreneurs are full of creative ideas and without doubt, are the future leaders of the country. However, to be a successful leader of a country or a business, one needs to be well equipped with key leadership skills such as postulated by Lippitt (2002).

Generally, in Asian model there is hierarchy, patriarchy, authority, is all that made the system works, but in modern times, debates has been raging in the popular management literature concerning whether leading and managing are different behaviours. One of the principal differences between leaders and managers is the ability to influence change. Managers support the direction and oversee processes vis managers create stability. Whereas leaders create necessary changes and set the direction in order to thrive in the modern economy and in a sustainable manner. Fundamentally, leaders use their collaborative and communication skills to gain the trust of people. The word "trust" is the root of influence. Only when our bosses trust in our ability, will they listen to our opinions and at that moment, we will have gained influence. It is the ability to influence others that gives a leader his or her power. It is the leader that creates the vision and uses their influence with others to make the vision a reality. Without the leader setting the course and navigating through those ups and downs that frequently occur, the organisation is likely to be in the doldrums. Hence, a lack of leadership chokes any organisational progress.

\subsection{Leadership Styles versus Productivity in Myanmar}

Myanmar's development has been gathering pace since its economic liberalisation began a few years ago and this demands a leadership style that best suits the stage of development.

Interestingly, the term "managers" is more identifiable than "leaders" and is used interchangeably here in Myanmar. Managers employ diversified styles to motivate the employees to produce their utmost. There are four (4) dominant leadership styles namely:

(a) Autocratic - an autocratic manager is one who scarcely seeks input from his employees to make decisions. This style of management can have an advantage in a fast-paced work environment in which quick decisions are needed to be made for daily routine tasks. Under this management style, managers tend to motivate their employees by establishing confidence in the manager's ability to make accurate and productive decisions. Employees are comfortable with the manager's knowledge on the industry and the company processes, and employees are motivated by their manager's ability to keep their department or factory focused upon achievement of company goals.

(b) Democratic - this democratic manager allows their employees to be involved in the decision-making process. They scarcely make important decisions without seeking the agreement of their employees. Their method of motivating their employees is inclusion vis-à-vis making the staff participate in the decision-making process that keeps the department running smoothly. Employees take an emotional interest in the success of their department because they can contribute towards formulation of departmental policies and process.

(c) Delegative - there are also those managers who sit back and just permit their employees to make the decisions affecting the daily routine tasks. This type of management is most effective with proactive and highly trained staff. These quiet leaders motivate their teams by playing the role of a resource person who provides information as and where necessary. They allow their employees to dictate their own success. 
If an employee's production begins to decline, the quiet leader will offer a developmental programme to help get the employee back on track.

(d) Transformational - under this style of leadership, a leader is a charismatic manager who opines that he has a vision for the future of the company that will bring success to all staff. Leaders or managers of this type motivate their staff by making effort to get the employees enthusiastically on board with their ideas for the future and then continually uses the vision of a more brilliant future as an incentive or motivation for their employees to be more productive. The transformational leader formulates a comprehensive plan for success that he delivers to employees and explains how each employee will have a role in the success of the organisation. In a nutshell, the organisational productivity is influenced by the style of leadership.

As the interconnectedness of Myanmar companies with global companies intensifies, the pace of change therefore increases, and the idea of flexibility comes to the fore, making it very important part of the global leadership competencies. Needless to say, without flexibility, there can be no constructive change moving towards the future. When business managers acquire global leadership competencies vis-a-vis the capacity and disposition to understand and act on issues of global significance, they will become effective and successful because of the comprehensive mindset that is endemic to all global leadership competencies.

\subsection{Effective Leadership}

Writers like Morrison (2000), Story (2011), Cseh et al (2013) all asserts that global leadership models must draw from many academic disciplines to be able to know and appreciate the differing business environment across the globe. Applying a multi-disciplinary approach, leaders are then able to understand the communities where the firm is present and have the capacity to work with and motivate people to a common goal in the different cultures. The model also advocates that domestic leadership models that work in a particular country may not necessarily work in the global environment (Morrison, 2000).

Within the developed economies like Singapore, Japan, UK and US, the notions of long-term efficiencies are common in leadership. Conversely, the short-term inefficiencies is not always consistent with the culture and the realities in the global marketplace, so there must be a new leadership approach within the context of organisational aims and global realities. How to develop a workable and practical model for global leadership? The central point of Mathew's (2016) article is that to develop a workable and realistic model for global leadership, the organisation must understand how the model should be structured so as to consider the need for culture, global strategy, and the leadership competencies that are needed to drive the organisation forward successfully vis-à-vis people within the organisation that have the knowledge, skills, and abilities to teach and train on this multi-disciplinary approach.

As noted by Kim \& McLean (2015), to operate as an effective leader in an era of globalisation, it is crucial to recognise which leadership behaviours are universally perceived as effective or characteristically appropriate to a certain culture. However, it is uncertain what the leadership behaviours that are considered effective globally are. Furthermore, Morrison (2000) pointed out that there is a lack of research identifying which effective leadership behaviours are shared across cultures or which behaviours are identified as indigenous in some cultures.

\subsection{The Trouble with Digital Transformation}

Despite growing acknowledgement of the need for digital transformation for both big and small enterprises, particularly in Myanmar, they lack sufficient management and relevant expertise as how to drive transformation through technology successfully. Even when businesses demonstrate it can leverage technology, it can still face challenges with new digital technologies. These technologies, for example, include social network sites (SNS), analytic, big data and smart devices; and they demand mind growth (Low, 2012) and skill sets than previous waves of information technology. There is no one single factor that impedes digital transformation in Myanmar, but due to the lack of urgency, diverse cultures, ethnicity and organisational constraints, etc.

Technology has indeed created an extraordinary amount of data, within this data there is huge potential for business leadership, but it also can be daunting. The internet of things has exponentially increased the amount of data generated. It provides visibility for business practices and can help identify bottlenecks and find efficiencies. However, this data can be useless if a company's systems and employees are not prepared to leverage it.

\subsection{Agenda for Future Enquiry}

In developing a roadmap towards digital transformation is challenging for leadership for two reasons vis what to transform first (a) customer relationship or (b) internal operations. Digital transformation in the first place starts with a vision from top leadership which there must be a huge buy-in; otherwise it will surely be destined for disaster. Thus reframing the questions about the business is a real challenge, as it necessitates a company to challenge its own assumptions about itself. 
Adaptability and attitudes of older workers may be problematic as there is a perception that older people are technophobic and not receptive to changes. Interestingly, company's top management is typically comprised of old people from 55 years and above and they too are not technological savvy and reluctant to change their "old" traditional ways of doing things. Older managers need to understand that their age can inhibit confidence in their ability and interest in leading digital transformation. Older managers can also obstruct changes that dictate less power, for example, fear of losing power in the company when adopting digital technology. There are sufficient resistances from organisational and cultural dynamics that not having clear structures makes it dicey for workers to push fir digital transformation. Digital transformation is efficacious only when the entire company aligns around the common vision. How or what else can a company do other than providing better incentives to implement digital transformation such as bonuses, promotions and performance reviews.

Today's situation is analogous to the acceptance in electricity by companies over a century ago. On the hindsight, it seems preposterous that leaders faced similar dilemmas then. It is worth mentioning that organisations who did not transform to maximise electricity then would fail. In this respect, the pace of digital acceptance in today's business and social environment is abundantly clear, so much faster than electricity uptake. Leaders need to digitally lead now. They need to digitally transform their organisations or risk being left behind.

At the organisational level, digital transformation lays the groundwork for innovative ideas. It provides a new framework for a business, it enables employees to do their jobs better, and, when successful, it frees up time and space for higher level work that can lead to business innovation and opportunities. This is vital because today's businesses are competing on a global scale not just domestically.

\subsection{The Effect of Post-modernism on Management and Leadership}

We turn now to the macro-societal question. The past several decades have seen a dramatic shift from a traditional topdown organisational system which is based on getting work done through people to the new emergent system which is based on knowledge and human creativity. Post-modernism management defines the management components somewhat dissimilar manner. For example, the components of planning, organising, staffing, coordinating and controlling in the post-modernism management are defined as innovation, active organising, encouraging, both entrepreneurship and self-control, respectively (Mirsepasi, 2004). The contemporary archetype based on rationality and the logic of efficiency, provided valuable service to companies in the era of modernism, where the primary focus was on mass production and construction of basic machineries. In fact, growth and development of organisations in the era of modernity resulted from the valuable activities of people such as Durkheim, Weber, Taylor and others. But in the post-modernism organisations, focus is on the empowerment of people and to help us do things in a smarter and efficient manner using artificial intelligence (AI) as an enabler.

According to McCrimmon (2006), postmodern leadership is based on some form of knowledge or insight, like thought leadership, that one person or group either adopts first to lead by example or advocates to others. Leadership has always been based on power. Now it is the power of knowledge rather than that of position or personality. It is an influence process where what is influenced is a change in direction, not necessarily performance improvement.

In the new thinking, leader is not solely grounded on the logical legitimate position. Similarly, leadership is not dependent on the valuable exchanges with others, to influence them, but there is an emphasis on the ability of the leader's personality and his influence on the beliefs, values, attitudes and actions of others (Hao \& Yazdanifard 2015). This leads to rational models to be conjoint with irrational models (based on intuition, charisma, etc.). Invariably these differences put pragmatic leaders against transformational leadership. The pragmatic leadership is interested in improving the quality of performance through exchanges in superior-subordinate and enhancing motivation in employees, whereas the transformational leadership is skewed towards a system of shared values and beliefs and force members to the new ways and efforts in achieving the goals (Tayal et al 2018). Likewise, innovative leadership are autonomous in decision-making and problem-solving, but post-modernism leadership investigate the rational decisionmaking.

Accordingly, what was ascribed to postmodernism on management theory, the formation and management of beyond modern organisations, it can be expected that a new world necessitates new organisations and new organisations are in need of new leaders.

\section{Limitation and Direction for Future Research}

This study has provided some insights of the impact of leadership style in the era of digital convergence and provided a possible agenda for future enquiry. The study does not seek to make generalisation of its findings as it studied with a small sample size. 
This may reduce the applicability and scope of the findings of the research in terms of generalisation in other organisations with similar mandate. Hence, future research should focus on broadening the scope to include leadership style and its relationship among different organisations with similar mandate.

\section{Conclusion}

In returning to the theme of leadership in the era of digital convergence, we should not be so obsessed on who is the person in charge as the society and work culture has changed. Industrial era concepts of leadership have worked well then, but it is unsustainable and has no survival value in a rapidly changing world and digital society. As business is increasingly populated with knowledge workers (Richard Florida's "creative class") they want to have a say, and not simply following blindly. Hence to encourage creativity and innovation and engaging innovative knowledge workers to the maximum, we must face the reality that they are the real leaders, not those in charge.

With escalating globalisation, diverse partners and multi-faceted businesses within the larger context of cross-cultural environment, leaders will be challenged to manage relationships more than in the past. This will include the ability to interact and capacity to lead matrix organisations vis-a-vis groups. Moving forward, predictions are that global economic prospects are clouded with moderating activity and heightened risks. The international trade and investment are likely to soften and trade tensions remain elevated; some large emerging market and developing economies (EMDEs) will experienced substantial financial market pressures. Against this challenging backdrop, EMDE growth will stall, with a sharply weaker-than-expected recovery in commodity exporters accompanied by a deceleration in commodity importers (World Bank 2019). This will truly require global leaders. As we have tried to elucidate, the changing global environment is likely to continue to stimulate the transformation and revitalisation of public and private organisations. Small as well as large MNCs (multinational corporations) accept they will have to change in order to compete in the global marketplace. This necessitates extensive change that must be accomplished in short periods of time. Such transformations require a new set of leadership skills and a good working definition of leadership.

To this end, leaders may need to follow different styles of leadership depending on the surrounding circumstances. For business firms in a postmodern society, transformational with digital acumen seems to be more appealing both for being consistent with postmodern mindset. Since transformational leadership pushes for power within, it can be used to develop a person's sense of self-knowledge and self-worth. This includes a capacity to identify and respect diversity of backgrounds and opinions. It is abundantly clear that the effective leaders of the twenty-first century will be one who encourages leadership growth and inspires workers to assume his or her role as a leader. Individuals working in twentyfirst century global organisations must be innovative and creative, tech-savvy, practice life-long learning, have moral beliefs that especially include integrity, have a personal vision, be responsible for personal growth, motivate from within, plan, communicate, and seeking harmonious relationships with all stakeholders.

\section{References}

Bergquist W.H. (2008). Leadership in Premodern, Modern and Postmodern eras, retrieved from

https://williambergquist.wordpress.com/2008/11/10/16-leadership-in-premodern-modern-and-postmodern-eras/. (Access date 24 April 2019).

Bird Allan, Mendenhall Mark, Stevens Michael J., Oddou Gary (2010). Defining the content domain of intercultural competence for global leaders, Journal of Managerial Psychology, 25(8), 810-828.

Creswell, J.W. (2007). Qualitative Inquiry and Research Design: Choosing among Five Approaches. Thousand Oaks, California: Sage Publications Inc.

Cseh Maria, B. Davis Elizabeth, E. Khilji Shaista, (2013). Developing a global mindset: learning of global leaders, European Journal of Training and Development, 37(5), 489-499.

Ford David L., Kiran M. Ismail (2008), Perceived Leader Effectiveness across Organizational Roles: Exploratory Evidence from Central Eurasia, Eurasian Journal of Business and Economics 2008, 1 (2), 131-156.

Fitzgerald Michael, Kruschwitz Nina, Bonnet Didier, Welch Michael (2013). Embracing Digital Technology, A New Strategic Imperative, MIT Sloan Management Review, Research Report.

Friedman, B.A. (2007). Globalization implications for human resource management roles. Employee Responsibilities and Rights Journal, 19(3), 157-171.

Ganta, V. C. and Manukonda, J. K. (2014). Leadership During Change And Uncertainty InOrganizations. International Journal of Organizational Behaviour \& Management Perspectives, 3(3), 1183.

Goncalves Marcus (2013). Leadership Styles: The Power to Influence Others, International Journal of Business and Social Science, 4(4).

Grint, K. (2007). What is Leadership? from Hydra to Hybrid. Working paper, Said Business School and Templeton College, Oxford University. 
Hao Moo Jun and Yazdanifard Rashad (2015). How Effective Leadership can Facilitate Change in Organizations through Improvement and Innovation, Global Journal of Management and Business Research: A Administration and Management 15(9).

Ho, R. C. and Teo, T. C. (2019). Consumer Socialization Process for the Highly Connected Customers: The Use of Instagram to Gain Product Knowledge, in Ho, R. C. (Ed), Strategies \& Tools for Managing Connected Customers, IGI Global, Pennsylvania. (Book chapter accepted for publication in July 2019).

Jackson Brad and Parry Ken (2008). A Very Short, Interesting and Reasonably Cheap Book About Studying Leadership. London: SAGE Publication, 208(2), 25.

Jeong Shinhee, Lim Doo Hun, and Park Sunyoung (2017). Leadership Convergence and Divergence in the Era of Globalization, Handbook of Research on Human Resources Strategies for the New Millennial Workforce, IGI Global.

Kim Junhee and McLean Gary N. (2015), An Integrative Framework for Global Leadership Competency: Levels and Dimensions, Journal of Human Resource Development International, 18(3).

Kreitner Robert, Kinicki Angelo (2001). Organizational Behavior, McGraw-Hill Higher Education, 5th Edition, Irwin/McGraw-Hill, ISBN 0072315008, 9780072315004.

Kreutzer Ralf T., Neugebauer T., Pattloch Annette (2018). Digital Business Leadership, Digital Transformation, Business Model Innovation, Agile Organization, Change Management, Springer, Berlin, Heidelberg. ISBN 978-3-662-565476.

Lee, P., Gillespie, N., Mann, L., and Wearing, A. (2010). Leadership and Trust: Their Effect on Knowledge Sharing and Team Performance. Management learning, 41(4), 473-49.

Lippitt, M. (2002). The leadership spectrum. Palo Alto, CA: Davies-Black.

Low, K. C. P. (2018; 2013). Leading Successfully in Asia, Springer: Heidelberg, Germany/ U.K./ USA.

Low, K.C.P. (2012). Confucius, Learning And Mind Growth - Want to Be A Winner? Global Education Journal, Vol. 2012, (2), $118-134$.

Mathews, Jose (2016). Toward a Conceptual Model of Global Leadership, IUP Journal of Organizational Behavior; Hyderabad 15(2), 38-55.

Maxwell, J. C. (1993). Developing the Leader Within You, Thomas Nelson, Inc.: USA.

McCcrimmon Mitch (2006), Burn! 7 Leadership Myths in Ashes, Action Publishing Technology, Ltd. London, ISBN: 09780080-0-6.

Mirsepasi N. (2004). Management of human resources and labor relations, Tehran, Iran.

Montana, P. and Charnov, B. (2008). Management, New York City, NY: Barron's Educational Series.

Morrison, Allen J. (2000). Developing a global leadership model, Human Resource Management, 39(2-3).

Northouse, P. (2009). Introduction to leadership: Concepts and practice. Thousand Oaks: Sage.Park Sunyoung, Jeong Shinhee, Jang Soebin, Yoon Seung Won, Lim Doo Hun (2018). Critical Review of Global Leadership Literature: Toward an Integrative Global Leadership Framework, Human Resource Development Review, 17(1), 95-120.

Shamir Boas, Eilam-Shamir Galit (2018), What's Your Story? A Life-Stories Approach to Authentic Leadership Development, in Israel Katz, Galit Eilam-Shamir , Ronit Kark, Yair Berson (ed.) Leadership Now: Reflections on the Legacy of Boas Shamir (Monographs in Leadership and Management, (Volume 9) Emerald Publishing Limited, pp. $51-76$.

Story, Joana S. P. (2011). A Developmental Approach to Global Leadership, International Journal of Leadership Studies, 6(3).

Tayal Ritu, Upadhya Rajesh Kumar, Yadav Mohit, Rangnekar Santosh, Singh Reena, (2018). The impact of transformational leadership on employees' acceptance to change: Mediating effects of innovative behaviour and moderating effect of the use of information technology, VINE Journal of Information and Knowledge Management Systems, 48(4), 559578.

Thompson, A. A., Peteraf, A.P., Gamble, E.\& Strickland, A.J. (2017, 21st edition). Crafting and Executing Strategy. The quest for Competitive Advantage: Concepts and Cases. New York : McGraw Hill Education.

Wasim, A. and Imran, A. (2010). The Role of Leadership in Organizational Change. Relating the successful organizational change to visionary and innovative leadership, Master's Thesis in Industrial Engineering and Management, Faculty of Engineering and Sustainable Development, University of Gavle.

World Bank (2019). Global Economic Prospects, retrieved from

http://www.worldbank.org/en/publication/global-economic-prospects (Access date 19-April 2019).

Wuestman, D., C.M.A., \& Casey, J. (2015). Lean leadership: Sustaining long-term processchange. Strategic Finance, 96(8), $15-16,61$.

Yukl Gary A. (1998). Leadership in Organizations, 4th Edition, Prentice Hall, ISBN $\quad 0138975213,9780138975210$. 